\section{Mídias participativas e violências extremas: uma etnografia on-line dos tiroteios em escolas}

PATON, Nathalie. School shooting: la violence à l'ére de YouTube. Paris, Maison des Sciences de l'Homme, 2015. 224 páginas.

\section{Tiago Hyra Rodrigues}

Em 1996, um adolescente de 14 anos invadiu armado sua escola nos Estados Unidos, entrou na classe de álgebra e matou dois colegas e a professora. Depois desse fato, Rage, romance de Stephen King publicado em 1977, virou alvo do debate público. O garoto Barry Loukaitis o teria lido várias vezes e nele se inspirado, e King foi acusado de ter estimulado o jovem a passar do pensamento ao ato, já que o livro relata em primeira pessoa, do ponto de vista do "estudante/matador", como ele toma seus colegas (justamente do curso de álgebra) como reféns. Seguindo o desenrolar da polêmica, o autor termina por solicitar a retirada de Rage de circulação, mas isso não irá impedir que o fenômeno continue a se reproduzir em escolas de todo o planeta.

School shootings é a denominação em língua inglesa para o fenômeno dos tiroteios em escolas, em que um aluno ou ex-aluno tem por alvo sua instituição, com o objetivo de fazer o maior número possível de vítimas antes de, frequentemente, se suicidar. Como compreender o desencadeamento dessa violência extrema? De que forma as mídias são responsáveis pela sua propagação? Como as novas tecnologias digitais afetam esse cenário? Esse é o tema da obra, fruto da tese de doutorado da socióloga francesa Nathalie Paton, orientada pela brasileira Angelina Peralva. Tendo como principais fontes os vídeos postados no YouTube pelos autores dos tiroteios e por seus "fấs", Paton tenta decifrar as intenções desses matadores, que, como ela pretende demonstrar, respondem de maneira singular às injunçôes contemporâneas de ser um indivíduo e de se realizar como pessoa.

Embora reconheça que Stephen King antecipou o advento desse tipo de violência, Paton utiliza como ponto de partida de sua pesquisa justamente os detalhes que ele deixou escapar. Entre eles, a importância das mídias na estruturação e na propaga- ção desses fenômenos violentos, coproduzidos pela imprensa e pelos autores dos tiroteios como eventos midiáticos de envergadura global, como no caso de Columbine, em 1999. ${ }^{1}$ Além disso, King não pôde prever o surgimento da internet, das redes sociais digitais e, consequentemente, o fato de que os school shootings seriam discutidos publicamente, criariam redes de sociabilidade entre os internautas e seriam premeditados on-line. Os atiradores de Columbine documentaram cuidadosamente a preparaçáo de seu projeto assassino em diários, gravaçôes audiovisuais e em seus blogs. Mais tarde, outros atiradores escolares foram além: criaram e divulgaram pacotes multimídia (contendo vídeos, fotos, músicas, manifestos) segundo as convençóes narrativas dos telejornais, com a esperança de que fossem difundidos e contribuíssem para modelar a imagem que seria proposta de suas identidades e das razóes que os levaram a agir.

Muito já se discutiu sobre as maneiras através das quais as diferentes formas de violência são ensinadas, aprendidas, imitadas e incorporadas, bem como acerca da influência das mídias sobre o comportamento. Para Paton, o debate (acadêmico e social) tende a apontar um efeito de causalidade entre o consumo de bens culturais ultraviolentos, como filmes e jogos, e o desenvolvimento de comportamentos desviantes: ao exporem atos de violência ao público, as mídias estimulariam a sua reprodução. $\mathrm{Na}$ versão mais radical da discussão, livros, filmes e jogos violentos são apreendidos como uma formatação para matar, dessensibilizando os consumidores da brutalidade e aumentando sua agressividade. Nessa perspectiva, os school shootings são remetidos a um efeito copycat (efeito de imitação), no qual as mídias, ao desvelarem um modus operandi, incitariam espectadores passivos a agir segundo o mesmo roteiro. $\mathrm{Na}$ versáo mais atenuada do debate, os bens culturais são entendidos como capitais de um "script cultural": difundindo uma visão hipernormativa da masculinidade no imaginário do público, as indústrias culturais seriam responsáveis por glorificar o recurso à violência e às armas, consideradas maneiras legítimas de resolver problemas interpessoais e de reestabelecer um status social. Aqui, a origem dos school shootings estaria numa forma de socialização ligada ao consumo cultural que con-

RBCS Vol. $32 n^{\circ} 94$ junho/2017: e329405 
duziria à "reprodução" de roteiros difundidos pela indústria cultural.

Para a autora, no entanto, o debate enfoca demais o poder que as mídias teriam de formatar o comportamento humano, em detrimento das formas pelas quais os indivíduos se servem das mídias. É necessário entender o que se passa quando a indústria cultural mainstream não é mais o único produtor de conteúdos culturais: como se relacionam mídia e violência quando as novas tecnologias digitais e as mídias participativas permitem que qualquer um com acesso a um computador ou smartphone difunda suas opiniōes e experiências para todo o planeta?

Para ir além das abordagens precedentes, centradas na influência midiática sobre os indivíduos, Paton se interessa, de maneira original, pelos conteúdos criados pelos atiradores para entender o que podem revelar das lógicas sociais subjacentes a essa forma de violência. Ela considera, porém, que as produçóes midiáticas dos assassinos dizem pouco sobre os school shootings, e muito sobre os próprios indivíduos. Na contramão dos estudos anteriores, sua análise enfoca mais os usos das mídias pelos indivíduos (e ao sentido que tais usos têm para eles) do que a influência das mídias sobre os atos dos indivíduos, ou seja, o que as mídias "fazem os indivíduos fazerem" (p. 51).

Deixando de lado as mídias como um objeto para se valer delas como um método, Paton busca identificar as razóes pelas quais os school shootings se tornaram um alicerce para a emergência de uma "subcultura", como a autora denomina. Oriunda de uma tradição sociológica que inclui Alain Touraine e Michel Wieviorka (assim como o centro de pesquisas criado pelo primeiro, o CADIS - Centre d'Analyse et d'Intervention Sociologiques), $\mathrm{Pa}$ ton segue uma perspectiva que trata do elo entre violência e produção de si mesmo como sujeito autônomo, reafirmando a importância dos processos de individuação e subjetivação para as análises sobre a violência. Assim, opóe-se a certas correntes pseudoestruturalistas e/ou deterministas, que submergem os indivíduos em processos institucionais e sistêmicos, dentro dos quais não teriam nenhuma margem de manobra.

Com o objetivo de conectar tal base teórica com os estudos sobre as mídias e com a análise dos school shootings, Paton busca compreender, de um lado, como o uso das mídias participativas modifica o fenômeno dos school shootings, e, de outro, de que maneira os school shootings podem ser indícios das contradiçóes da injunção contemporânea de individuação.

Inicialmente, ela apresenta os debates sobre o fenômeno e discute como a responsabilidade das mídias foi questionada sobre a propagação dessa forma de violência à escala internacional. Os school shootings eram associados, nos anos 1980 nos Estados Unidos, à violência entre gangues e a disputas de mercados de drogas por jovens negros e hispânicos. Mas, nos anos 1990, uma série de tiroteios em escolas situadas fora dos territórios das gangues veio questionar essa geografia e o repertório de causas que permitiam explicar esses eventos. Como tentativa de explicação, foi forjada a expressão "superpredador", que pretendia sinalizar o surgimento de uma geração de jovens que seria "impiedosa e desprovida de moral” (Dilulio, 1995). Tal ideia foi reforçada por outras características que fazem dos school shootings uma forma de violência atípica, como o fato de os matadores parecerem não ter alvos claramente estabelecidos, remetendo a uma forma de violência "irracional" em oposição à violência mais comum (socioeconômica, por exemplo). ${ }^{2}$

Ademais, essa violência também é atípica em outro quesito: os autores dos tiroteios seriam "meninos invisíveis" - jovens certamente isolados e solitários, mas que não apresentavam sinais de problemas comportamentais. Seus atos parecem ainda mais incompreensíveis por serem alunos "normais", que seguiam os quadros normativos dominantes. Eram, na maioria, adolescentes brancos, de "boa família”, criados em pequenas cidades do interior ou nos subúrbios ricos das grandes cidades. Essa foi, ao menos, a maneira pela qual foram descritos nos debates públicos.

Segundo a autora, o massacre de Columbine representou uma virada nessas representaçóes, pois teve tal eco nas mídias mundiais que terminou por singularizar o fenômeno dos school shootings em face das outras formas de violência juvenil. Paton afirma que Columbine pode ser tomado como modelo operatório (ou tipo ideal) de todos os school shootings: ocorreu no interior do estabelecimento 
escolar; o fuzil foi a principal arma empregada (o arsenal pode incluir também facas, bombas artesanais, pistolas); os autores eram alunos (poderiam ser ex-alunos); teve múltiplos alvos, e numerosas vítimas (mortas ou feridas); os alvos, apesar de serem simbólicos (elite estudantil, esportistas etc.), foram escolhidos ao acaso; e os autores do massacre efetuaram-no com a segurança de morrer, seja se suicidando, seja se fazendo matar pelas forças policiais (ou suicide by cop).

Paton mostra como, depois de Columbine, os cientistas tentaram explicar o fenômeno com a ajuda de um feixe de causas convergentes de ordem psicológica, social, cultural ou histórica. Foram evocados os problemas psicossociais dos jovens assassinos, sua marginalização social, a disponibilidade de armas de fogo e os scripts culturais subversivos que valorizam esses massacres. Mas, com o passar dos anos, os massacres se internacionalizaram. ${ }^{3}$ Com a extensão geográfica dos casos, as variáveis do modelo explicativo foram reduzidas em proveito de uma psicologização do debate: as explicaçóes tenderam a ser circunscritas à personalidade dos assassinos, seus problemas psicológicos e aos atos de intimidação e de bullying dos quais teriam sido vítimas. Em paralelo, insistiu-se em explicar o desenvolvimento de comportamentos violentos nos jovens a partir de seu consumo midiático.

Além disso, a midiatização é tida como responsável pela epidemia assassina. $\mathrm{O}$ tratamento jornalístico dos school shootings é acusado de disseminar uma "cultura do medo" (Glassner, 1999) e de alimentar a difusão do fenômeno ao dar aos assassinos uma real notoriedade midiática, e mesmo um estatuto de celebridade. Assim, segundo Paton, ao perpetrarem um tiroteio escolar seguindo um roteiro predefinido, os assassinos dão provas de reflexividade: conhecem as repercussóes de seu gesto e o que acontecerá às suas imagens públicas se agirem de determinada maneira. A noção de script ou roteiro cultural é, portanto, mais sutil que simples influência passiva ou imitação; ela acentua a dimensão expressiva desses atos.

A originalidade do trabalho de Paton reside em levar em conta o papel que assumem as mídias participativas nesse contexto. No novo cenário digital, os usuários não podem mais ser reduzidos a seres passivamente influenciáveis, esponjas que absorvem informaçóes ou simples receptores; estão em posição de criar seus próprios produtos culturais. Assim, após cada school shooting, os usuários das redes digitais compartilham informações, discutem e prestam homenagem às vítimas, a priori longe de qualquer censura oficial, o que foi percebido como possível fonte de riscos. As dúvidas recaem principalmente sobre os internautas que apresentam tendências subversivas ou violentas e tomadas de posição radicais em relação aos school shootings. Paton os denomina, simplesmente, fẫs. Ao redor deles, cria-se uma espécie de "pânico moral" devido às suas posiçóes que beiram o extremismo e, principalmente, à possibilidade de serem os próximos candidatos a atiradores. ${ }^{4}$

Em resumo, se antes as mídias de massa eram apontadas como incitando à violência, com a expansão das mídias participativas houve uma mudança: em lugar de um efeito "de cima para baixo", que supõe a impregnação da violência através do consumo de bens culturais, agora são os efeitos perversos da cultura participativa e horizontal que são enfocados. Para analisá-la, Paton realizou sua etnografia on-line, organizada em torno de três enquetes específicas:

A primeira trata da constituição do "grande público" a partir da midiatização dos tiroteios, e particularmente da formaçáo de santuários digitais espontâneos no YouTube dedicados à memória das vítimas, e que Paton analisou tomando o caso do massacre de Virginia Tech, em 2007, como exemplo. 5 Segundo ela, o grande público condena, com maior ou menor firmeza, os school shootings. O consenso é acompanhado de uma expressão de profunda indignação.

A segunda enquete é relativa aos usos midiáticos de um "contrapúblico", os participantes da subcultura dos fấs de school shootings. Existem aqui vozes dissonantes e diferentes maneiras de interpretar os tiroteios e seus autores. Paton identifica aqueles que tentam "repolitizar a violência", expondo os conflitos sociais subjacentes e o surgimento de um movimento de resistência em face das injustiças do sistema escolar; aqueles que "comemoram", prestando homenagem não às vítimas, mas sim aos assassinos - seja para defenderem causas sociais 
(antibullying, por exemplo), seja para darem sentido às trajetórias de vida dos atiradores, sem com isso defenderem seu gesto, seja para alguns glorificarem a violência e conferirem aos matadores o estatuto de "heróis". Apesar disso, Paton sustenta que a participação midiática dos fẫs demonstra um trabalho reflexivo, de desconstrução do objeto: mesmo quando procuram justificar os massacres, tais justificativas são secundárias em relação ao desejo de se engajarem on-line para saírem da solidão e encontrarem outros internautas que partilhem as mesmas experiências.

A terceira enquete diz respeito aos pacotes multimídia produzidos e difundidos pelos autores dos tiroteios durante a fase de premeditaçáo dos ataques. Aqui o mimetismo fica claro: vídeos extremamente parecidos, mesmo fundo musical, roupas e expressóes corporais idênticas. A semelhança entre as fotos de Seung-Hui Cho (Virginia Tech) e de Wellington de Oliveira (Escola Tasso da Silveira), com as quais a autora ilustra a página 91, é impressionante. Entretanto, Paton procura se distanciar tanto das teses do "efeito de imitação" quanto das que afirmam que os school shootings reproduzem um script cultural. Os jovens assassinos se imitam, mas, para ela, isso não é prova da influência das mídias, e sim sinal de uma estratégia de comunicação intencional da parte dos protagonistas.

Nos vídeos, eles fazem questão de afirmar que não são influenciados por ninguém e que o objetivo é que suas açóes sejam categorizadas como school shootings, com a finalidade de obterem, através desse roteiro de violência expressiva, uma notoriedade social póstuma. Nesse sentido, declara Paton, as mídias são menos uma influência que um recurso: são vetores de visibilidade, pois os atiradores criam canais para comunicar suas intençóes, mostrar quem são e o motivo de agirem dessa maneira. E o fazem utilizando o script cultural dos school shootings, representando-se como superpredadores ou modelos de virilidade. Logo, para a autora, isso não é banal imitação passiva.

O vasto conjunto semiótico reunido por ela parece confirmar que os atiradores reutilizam ostensivamente os mesmos significantes subculturais para moldar sua associaçáo ao fenômeno dos school shootings. Ou seja, imitam-se com o objetivo de serem reconhecidos como autores de determinada forma de violência (os school shootings), como matadores e anti-heróis, para ascenderem ao grau supremo da hierarquia social, o de celebridade. É uma aposta identitária, inscrita no fundamento dessa forma de violência, que se revela a principal reivindicação que transparece em seus vídeos e na forma pela qual se apropriam dos recursos midiáticos participativos. Trata-se de colocar à prova sua individualidade, redefinindo sua identidade em termos valorizantes. Enquanto o ataque propulsa os jovens às manchetes, o emprego das mídias participativas lhes dá a impressão de poder controlar suas imagens e redefinir a forma como são vistos.

Mas isso nos diz pouco sobre as razóes pelas quais os assassinos decidem agir ao invés de simplesmente engrossarem as fileiras dos făs. Assim, no último capítulo, Paton defende a hipótese de que o desenvolvimento dessas práticas é apenas reflexo de um paradoxo contemporâneo, relativo à imposição de autonomia individual que convida cada um a se diferenciar, a dar provas de sua singularidade e do sucesso de sua individuação. A participação na subcultura dos school shootings, por mais subversiva que seja, traduz uma forma contemporânea de se individuar, afastando-se das normas e papéis sociais prescritos.

No registro discursivo dos vídeos dos assassinos, instala-se uma dupla tendência narrativa de "encenação de si": de um lado, atribuem-se à parte mais baixa da pirâmide social, afirmam sua marginalidade, negam sua pessoa, se colocam em posição de fraqueza: são losers (perdedores), patéticos, idiotas; de outro, comunicam sua diferença, mostrando sua excepcionalidade com a ajuda de qualificativos como "super-homem", "deus reencarnado" e "ser divino". Para Paton, tal passagem do fraco ao forte assinala que esses jovens constroem uma imagem de si mesmos fundada no registro da dominação, sendo por vezes dominados e por vezes dominantes. O projeto do ataque permitiria a "virada de mesa" e a redefinição de suas identidades, retirando-os da postura de fragilidade. A violência extrema seria um recurso para se diferenciarem e alcançarem a notoriedade que almejam. Assim, para a autora, o processo que leva à violência tem relação com a individuação, ou seja, a produção de si mesmo como indivíduo autônomo, empreendido por 
alguns jovens através da destruição e do caos.

Trata-se, de fato, de um exemplo original de individuação. Utilizando as ferramentas de que dispõem (a "celebrização", via instrumentalização das mídias participativas e da imprensa), os jovens assassinos atraem a atenção sobre as injustiças que sofreram, assim como sobre a individualidade sob medida que fabricaram. No entanto, há aqui um paradoxo do qual não podem fugir: a obrigação de cada um de se autodefinir e desejar a diferença, quando a diferenciação já se tornou a norma. A própria subcultura aparece como uma espécie de conformismo em relação ao grupo. Assim, eles não fazem nada além de se submeterem às normas sociais contemporâneas, à cultura hipermasculina e violenta das armas, assim como às injunçóes de "se realizarem como pessoas", de serem "empreendedores de si mesmos". Simplesmente, eles o fazem pela violência.

\section{Notas}

1 Dois atiradores, um com 17 anos e outro com 18, planejaram e executaram um ataque à Columbine High School, em Denver, Colorado (EUA), matando 12 alunos e um professor. Depois se suicidaram na biblioteca da escola.

2 Para Paton, essas matanças são, no entanto, dotadas de racionalidade própria. Os adolescentes não tiveram um simples colapso nervoso, como dizia a imprensa da época. Suas ações não são expressóes de uma loucura passageira: esses tiroteios são premeditados e planejados com antecedência, o que demonstra sua racionalidade.

3 Casos de school shootings ocorrem por todo o planeta, e mesmo no Brasil, na Escola Municipal Tasso da Silveira, no Rio de Janeiro, em 2011.

4 Foi o caso de Pekka-Eric Auvinen, membro de comunidades de fãs de school shootings no Youtube, que, em 2007, cometeu um school shooting em sua escola na Finlândia. Ele havia postado no Youtube vídeos que celebravam a memória dos assassinos de Columbine.

5 Na Universidade do Estado de Virgínia (EUA), um estudante de 23 anos matou 32 pessoas e feriu outras em dois ataques seguidos em locais diferentes do campus. Ele próprio também se matou. Dois dias depois, uma rede de TV recebeu um pacote com texto, fotos e vídeos do planejamento do massacre, o qual denominou "Manifesto Multimídia", e que fora enviado pelo atirador durante o intervalo de duas horas entre um e outro ataque.

\section{BIBLIOGRAFIA}

DILULIO, J. (1995), "The coming of the super-predators". The Weekly Standard, I (11): 23. Disponível em: <http://www.weeklystandard. com/the-coming-of-the-super-predators/article/8160>. Acesso em: 15 jul. 2016.

GLASSNER, B. (1999), The culture of fear: why Americans are afraid of the wrong things. Nova York, Basic Books.

TIAGO HYRA RODRIGUES é bacharel e licenciado em ciências sociais pela Universidade de Sáo Paulo, mestre e doutor em Antropologia Social pela Universidade Federal de Santa Catarina. É pesquisador associado ao Centre d'Analyse et Intervention Sociologiques (Cadis EHESS/CNRS - França), onde atualmente realiza pesquisa pós-doutoral. E-mail: tiagohyra@gmail.com

DOI: $10.17666 / 329405 / 2017$ 